\title{
INVESTIGATING FINANCIAL PERFORMANCE OF LOW-AND HIGH- RATED ETFS DURING THE QE-TAPERING
}

\author{
Nikolaos GALATIS ${ }^{1}$ \\ Ekaterini NITSI ${ }^{2}$ \\ Chrysoula THELOURA ${ }^{3 *}$
}

Received: December, 2018 | Accepted: April 2019/February 2020 | Published: April 2020

Please cite this paper as: Galatis, N., Nitsi, E., \& Theloura, C. (2020). Investigating Financial Performance of Low-and High-Rated ETFs during the QE-Tapering, Holistica Journal of Business and Public Administration, vol. 11, iss. 1, pp. 107-123

\begin{abstract}
This paper investigates the financial performance of 37 low-rated and high-rated global ETFs during QE-Tapering. Weekly data are employed that cover the period from October 27, 2014 until September 24, 2018. The estimations are based on the well-known CAPM model. The measures employed are the Sharpe and Treynor ratios as well as the Jensen's alpha, the beta and the $a / b$ measures. Results indicate no existence of selectivity skills neither in low-nor in high-rated ETFs. It should be noted that low-rated ETFs exhibit bearish behavior whereas high-rated ones present bullish behavior. Thereby, one can see that high-rated ETFs are better able to outperform the market during periods of normalization of monetary policy after extra easing action taking has been terminated.
\end{abstract}

Keywords: Beta; CAPM; selectivity skills; mutual funds; coefficient; Jensen's alpha; Sharpe; Treynor

\section{Introduction}

A proliferating bulk of academic interest has been aroused since 2008 when the Lehman Brothers collapse took place. This collapse triggered the Global Financial Crisis that resulted in a meltdown in financial markets and the real economy. Due to the inability of monetary authorities to be efficient at the Zero Lower Bound (ZLB) unconventional action taking took place. Quantitative easing (QE) has been mainly expressed in the form of

\footnotetext{
${ }^{1}$ Department of Economics, University of Thessaly, $28^{\text {th }}$ October 78, P.C. : 38333 Volos, Greece, galatis@uth.gr

${ }^{2}$ Department of Economics, University of Thessaly, $28^{\text {th }}$ October 78, P.C. : 38333 Volos, Greece, anitsi@uth.gr

${ }^{3}$ Department of Economics, University of Thessaly, $28^{\text {th }}$ October 78, P.C. : 38333 Volos, Greece, ctheloura@uth.gr

* Corresponding author
} 
large-scale asset purchases (LSAPs). Thereby, huge amounts of liquidity were injected in major economies by their central Banks. These out of the ordinary economic and financial conditions have greatly altered the way of thinking of investors as well as policy makers (Fawley \& Neely, 2013; Joyce et al, 2012).

One of the most sophisticated expressions of financial instruments have been exchangetraded funds (ETFs), which constitute a modern form of the traditional mutual funds. An ETF is a marketable security tracking an equity index, a commodity, bonds, or a basket of securities despite its many similarities with mutual funds, they are not identical as shares trade like common equity on an exchange. The quote of an ETF's shares will fluctuate during the day because of their trading. The largest ETFs exhibit higher average daily volume and are less costly in comparison to mutual fund shares. This renders them an attractive option to contact investment actions.

QE-tapering or taper tantrum had been launched in mid-2013 by the Maturity Extension Program (MEP), according to Aizenman et al. (2014); Chari et al. (2017). QE-tapering signifies the normalization of monetary policy, as interest rates exhibit a tendency to be higher than the zero-lower bound. This has allowed sweeping up the extra liquidity that QE actions had infused in markets and the real economy. Thereby, investigating the behavior of investors during the taper tantrum enables interested readers to make out whether the performance of assets has been ameliorated or not during QE-tapering and stepping towards normal times.

In this study, an integrated examination is undertaken in order to assess the manager selectivity skills and the aggressiveness of investment decisions of a highly-sophisticated form of mutual funds in highly-turbulent eras. This fills a gap in relevant bibliography and we intent to provide a roadmap for further investigation. Up to the present, as far as we know, no other study has placed under scrutiny the behavior of global ETFs during QETapering.

The remainder of this study is as follows: Section 2 provides previous academic work on measurement of financial performance by employing the Sharpe and Treynor ratios and the Jensen's alpha, the beta as well as the a/b measures. Section 3 presents the data and the methodology employed in order to derive results. In Section 4, the econometric outcomes and assessments are laid out and the economic implications are developed. Finally, Section 5 offers the conclusions.

\section{Literature review}

A significant bulk of academic papers have investigated the financial performance of assets by employing Sharpe and Treynor ratios. In 1966, William Sharpe introduced a new measure in order to describe the performance of assets. There have been many alterations in the original test, due to the problem of test's validation when returns have tails heavier than normal distribution, according to Ledoit et al. (2008). A lot of changes have also occurred at the Treynor ratio. Hübner (2005) in his study does not employ the 
HOLISTICA Vol 11, Issue 1, 2020, pp. 107-123

traditional Treynor performance ratio concerning only one index but advances into a number of indices. The statistic employed, is known as the Generalized Treynor Ratio and presents very similar basic mathematical and analytical characteristics with the conventional Treynor measure.

A large amount of academic work has been realized in the field of selectivity skills, which is commonly referred as Jensen's alpha. To specify, Jensen (1968) argues that when timing capabilities are brought about, then there is a possibility that assessments of the market risk ar found to be skewed towards non-positive values. On the other hand, positive skewness is detected as regards selectivity skills. Chen and Jang (1994) investigate whether fifteen mutual funds covering a worldwide level but traded on the USA during the 80's decade 1980-89 present selectivity or timing capabilities and which is the level of importance of these capabilities for estimating performance. They employ the Treynor and Mazuy methodology modified by Lee and Rahman. They provide evidence that a large portion of the international mutual funds achieved better performance than the U.S. market benchmark. They employ an indicator of a global representativeness to play the role of the benchmark, and support that directors of funds exhibit weak selectivity skills. It is also found that heavy reliance exists on timing skills in international capital markets. Hallahan and Faff (1999) investigate whether a sector of investment funds in Australia that is, equity trusts, can demonstrate skills of capturing the momentum of the market, starting from late 80 s and ending in late $90 \mathrm{~s}$, by adopting quadratic and innovative beta representations. They document that only weak market timing is apparent and market timing specifications are almost equally capable to provide accurate explanations. Lhabitant (2001) investigate how sixty Swiss equity investment funds behave during the last twenty-two years of the 20th century. It can be documented that not market timing selectivity skills have been detected as well as no positive net payoff has been found achievable.

Romacho and Cortez (2006) adopt the methodology of Henriksson and Merton (1981) and reveal that managers of Portuguese mutual funds do not exhibit selectivity and timing abilities, and some of them even present negative timing. Moreover, it is found that fund managers that invest locally achieve better performance in comparison to those investing in foreign markets. Furthermore, there is evidence that International fund managers prefer market-timing strategies. Koulis et al. (2011) investigate the performance of fifteen Greek mutual equity funds. Since early 2000 to late 2008, by adopting the Treynor-Mazuy framework and Sharpe and Treynor ratios. Findings indicate that the domestic mutual equity funds under scrutiny do not present positive alphas and show weak timing skills in relation to the market, Ünal and Tan (2015) study the aplhas and gammas in Poland from early 2009 to late 2014 . Findings reveal that only one seventh of funds present selectivity skills, but results are robust. It should be noted that outcomes based on the Treynor \& Mazuy (1966) methodology reveal timing skills in two funds.

Blume and Friend (1973) reject the Capital Asset Pricing model (CAPM) to explain returns in financial assets. The beta coefficient has proved very popular in order to analyze the risk level of assets and portfolios. Furthermore, beta provides a reasonable degree of 
predictability over future time periods due to its ability to assess future portfolio risk and return as Klemkosky et al. (1975) support. Morgan (1975) adopts the minimum variance zero beta portfolio $z$ and assesses the risk-return nexus. Reinganum (1981) argues that equilibrium pricing is probably influenced but not totally dependent on an asset's beta. Pettengill et al. (1995) support the existence of a robust nexus between beta and crosssectional portfolio returns. In times of negative excess returns of a market portfolio, an inverse nexus with the systemic risk coefficient is brought about. When adjustment takes place for the expectations concerning negative such returns, a robust linkage with this coefficient is found. Additionally, a positive payment for beta risk is revealed.

Shanken (1985) argues that the CRSP equally-weighted index is inefficient. It should be noted that the efficiency cannot be attributed to by an effect due to firm size that begins early in the year and lasts until the end of the year. Bollerslev et al. (1988) adopt a multivariate GARCH process to assess performance of assets by taking the conditional covariance into consideration. Evidence indicates that the conditional covariances are not steady over time and comprise a significant factor of the time-varying risk premia. Furthermore, the implied betas are also time-varying and easy to forecast. Shanken (1992) provides an integrated econometric perspective of maximum likelihood specifications and more conventional two-pass methods to assessing beta-pricing models. He supports that the traditional inference does not provide precisely the price of risk estimates and an asymptotically valid correction is produced. Malkiel (2014) supports that smart beta portfolios do not consistently achieve higher returns and when they do this results in appealing outcomes.

The CAPM has enjoyed contributions by Sharpe (1964), Lintner (1965) and Mossin (1966). It indicates that an investor selects the best portfolio in terms of risk-return linkage based on the Markowitz specification. MacKinlay (1995) distinguishes between ex-ante and expost CAPM analysis. He argues that with ex-ante analysis CAPM deviations owing to not all risk parameters be taken into consideration leads to large difficulty to statistically be traced. Fama and French (1996) document that survivor bias does not explain the linkage between $\mathrm{BE} / \mathrm{ME}$ (book equity to market equity) and mean return. Moreover, they argue that annual and monthly betas produce very similar implications about the beta premium. They also claim that beta alone cannot explain expected return. Fama and French (2006) investigate the effect of the company's magnitude to value premia and the influence of the CAPM. They support that the CAPM suffers from serious drawbacks during the period 1926-2004.

Gastineau (2001) claims that there is a remarkable misunderstanding concerning how ETFs operate and to which industries ETFs fit better. He answers these and other queries important for investors. As Kotsovesky (2003) argues, ETFs seem to be suitable for investors aiming to link their asset to a market index of primary importance. Furthermore, Avramov et al. (2006), explain the usage of the US domestic equity mutual funds. Harper et al. (2006) conduct a comparison of how risk and return influence each other in the case of non-domestic markets and closed-end national ETFs from April 1996 to December 2001. Econometric outcomes denote that better performance is revealed in, while CEFs 
HOLISTICA Vol 11, Issue 1, 2020, pp. 107-123

exhibit no selectivity skills. Thereby, active management is not always preferable. Engle and Sarkar (2006) look into the size of premiums and discounts in a broad spectrum of ETFs. By contacting estimations on domestic funds with and without futures contracts find that the volatility of the premium is 14 bps on average. When it comes to the international funds, volatility is found to be much higher. Nevertheless, they may still be performing in tandem with expectations In a somewhat different vein, Islamic funds are investigated in the research of Hayat et al. (2011). Agapova (2011) indulge into investigating the nexus between conventional index mutual funds and ETFs. They support that conventional funds and ETFs are competitive but not fullu competitive for each other. The reasoning for this taking place is probably a clientele impact that divides the two vehicles into different market segments. Madhavan (2012) argues that the influence of the Flash Crash across equities is linked to prior market fragmentation. By employing intraday trade data from January 1994-September 2011, evidence is given that fragmentation now is at the highest level. Market structure reforms triggered since the Flash Crash should help confront future market disruptions.

\section{Data and methodology}

The data employed are in weekly frequency and spans the period from October 27, 2014 until September 24, 2018, that is the whole period of QE-Tapering up to the present is covered. All quotes are transformed into logarithmic differences. The variables under consideration represent 25 low-rated ETFs and 12 high-rated ETFs (ranked as one star and five stars, respectively, by the Morningstar rating agency). All values are extracted from the yahoo finance database. Tables 1 and 2 present the descriptive statistics of one-star and five-star ETFs, respectively.

Table 1 Descriptive statistics of one-star rated ETFs

Source: Authors contribution, 2018

\begin{tabular}{cccccccc}
\hline Variable & Obs & Mean & Std.Dev. & Min & Max & Skewness & Kurtosis \\
\hline SP500 & 204 & 0.00180 & 0.01548 & -0.06149 & 0.03731 & -1.00217 & 6.05868 \\
MDIV & 204 & 0.00032 & 0.01370 & -0.03865 & 0.04792 & -0.10122 & 4.31666 \\
IBDH & 204 & 0.00043 & 0.00249 & -0.00954 & 0.00990 & 0.57588 & 6.58610 \\
BSCI & 204 & 0.00029 & 0.00203 & -0.00752 & 0.00702 & -0.73560 & 5.79015 \\
RINF & 204 & -0.00028 & 0.02737 & -0.24392 & 0.23256 & -0.47507 & 57.24115 \\
ISHG & 204 & -0.00037 & 0.01037 & -0.02760 & 0.02753 & -0.12939 & 3.03855 \\
BIL & 204 & 0.00008 & 0.00047 & -0.00121 & 0.00197 & 0.58708 & 5.77263 \\
& & & & & & & \\
\hline
\end{tabular}


HOLISTICA Vol 11, Issue 1, 2020, pp. 107-123

\begin{tabular}{|c|c|c|c|c|c|c|c|}
\hline PVI & 204 & 0.00005 & 0.00086 & -0.00401 & 0.00320 & -0.18723 & 6.05601 \\
\hline IBMI & 204 & 0.00020 & 0.00270 & -0.00946 & 0.00910 & -0.11184 & 4.12068 \\
\hline SNLN & 204 & 0.00052 & 0.00466 & -0.01827 & 0.01719 & -0.36992 & 5.09646 \\
\hline $\mathrm{PIO}$ & 204 & 0.00073 & 0.01889 & -0.07539 & 0.05366 & -0.69993 & 5.04351 \\
\hline AGND & 204 & 0.00011 & 0.00672 & -0.01766 & 0.02046 & 0.29663 & 3.49510 \\
\hline EGPT & 204 & -0.00347 & 0.03843 & -0.29561 & 0.07861 & -2.37880 & 18.88352 \\
\hline HYLD & 204 & 0.00026 & 0.01251 & -0.08303 & 0.03629 & -2.08157 & 14.47047 \\
\hline BTAL & 204 & 0.00014 & 0.01723 & -0.07468 & 0.04906 & -0.45504 & 4.46125 \\
\hline SDIV & 204 & 0.00044 & 0.01869 & -0.05563 & 0.06074 & -0.17309 & 3.99986 \\
\hline KCE & 204 & 0.00109 & 0.02754 & -0.11996 & 0.09380 & -0.43020 & 5.20507 \\
\hline INKM & 204 & 0.00061 & 0.01027 & -0.03275 & 0.02724 & -0.14569 & 3.53354 \\
\hline SHYD & 204 & 0.00032 & 0.00454 & -0.02936 & 0.01005 & -2.16305 & 14.46254 \\
\hline SPFF & 204 & 0.00025 & 0.00847 & -0.03174 & 0.02985 & -0.32767 & 4.63290 \\
\hline EIS & 204 & 0.00105 & 0.01958 & -0.09681 & 0.04652 & -0.83898 & 5.49255 \\
\hline LVL & 204 & 0.00010 & 0.02181 & -0.07331 & 0.08170 & -0.01526 & 5.02144 \\
\hline USO & 204 & -0.00333 & 0.04606 & -0.12941 & 0.11753 & -0.20949 & 3.06562 \\
\hline IEF & 204 & 0.00017 & 0.00765 & -0.02979 & 0.01967 & -0.65751 & 4.31256 \\
\hline EELV & 204 & 0.00001 & 0.02076 & -0.07810 & 0.06305 & -0.41121 & 4.69879 \\
\hline KBWD & 204 & 0.00101 & 0.01995 & -0.09747 & 0.07076 & -0.51178 & 6.33475 \\
\hline
\end{tabular}

Source: Authors contribution, 2018

Table 2 Descriptive statistics of five-stars rated ETFs

\begin{tabular}{cccccccc}
\hline Variable & Obs & Mean & Std.Dev & Min & Max & Skewness & Kurtosis \\
\hline XBI & 204 & 0.00261 & 0.04190 & -0.16230 & 0.18780 & -0.12525 & 5.70511 \\
& & & & & & & \\
SLYG & 204 & 0.00274 & 0.02209 & -0.07483 & 0.09365 & 0.21681 & 4.94729 \\
QTEC & 204 & 0.00334 & 0.02384 & -0.08639 & 0.06248 & -0.73644 & 4.21169 \\
ARKW & 204 & 0.00531 & 0.02887 & -0.10220 & 0.07786 & -0.45717 & 4.06890 \\
ZROZ & 204 & 0.00049 & 0.02617 & -0.12020 & 0.06312 & -0.73893 & 5.06051 \\
\hline
\end{tabular}


HOLISTICA Vol 11, Issue 1, 2020, pp. 107-123

\begin{tabular}{cccccccc} 
RZG & 204 & 0.00260 & 0.02235 & -0.08720 & 0.10223 & -0.91241 & 5.65100 \\
CQQQ & 204 & 0.00147 & 0.03475 & -0.12096 & 0.09893 & -0.43381 & 3.84561 \\
SMH & 204 & 0.00383 & 0.02712 & -0.09325 & 0.06147 & -0.63711 & 3.44801 \\
SOXX & 204 & 0.00393 & 0.02883 & -0.09918 & 0.05832 & -0.62680 & 3.32649 \\
QLD & 204 & 0.00550 & 0.04289 & -0.15289 & 0.11010 & -0.81769 & 4.85957 \\
PSI & 204 & 0.00422 & 0.03032 & -0.09611 & 0.05844 & -0.61541 & 3.18662 \\
XSD & 204 & 0.00378 & 0.02959 & -0.09917 & 0.06928 & -0.50381 & 3.14427 \\
\hline
\end{tabular}

Source: Authors contribution, 2018

By studying the descriptive statistics, we reached the following conclusions: The highest average belongs to the KCE, the highest standard deviation is found at the USO and the maximum range between the highest and lowest quote of the observations belongs to the RINF Fund. It can be seen that most values of the particular time series are negative and this equals to the distribution being asymmetric to the left (negative asymmetric). In addition, the distribution is leptokurtic because the kurtosis tests reveal values higher than 3 , which means that greater opportunities appear for profit.

Table $1 \mathrm{~b}$ presents $12 \mathrm{ETFs}$, which are also reported in this period, with the only difference that they have been rated with 5 stars $(* * * *)$ by the Morningstar. Furthermore, the corresponding boxplots are depicted. The results of the data we investigate are as follows: The highest average belongs to the QLD fund, the largest standard deviation is found for the ZROZ fund and the maximum range between the highest and lowest quote of the observations belongs to the XBI. Skewness in the majority of ETFs is found to be negative so the distribution is negatively asymmetric. It can also be noticed that the distribution of most of ETFs is neither leptokurtic nor platykurtic as the corresponding quotes are very close to three (3).

Comparing the results of tables $1 a$ and $1 b$, the following can be seen: When studying the maximum average between the two categories of ETFs that are compared, it is evident that the higher one appears in the five-star category. This means that in the five-star rated ETFs we have higher returns than those of one-star rated star, which also validates Morningstar's assessment.

On the other hand, the higher volatility occurs in the one-star rated ETFs. A fact, that represents that the risk for investors to deposit their money in this category is far greater than what would have been the case if they preferred a five-star rated ETFs.

In terms of higher precision in results, one can make out that KCE is the ETF that presents the higher mean (0.0018). It is observable that only three out of twenty-five ETFs approach the highest mean value while the remaining twenty-two exhibit large deviations from this highest value. In contradiction, high-rated ETFs present a highest mean value equal to 0.0055 in the KLD ETF. It should be noted that four out of twelve ETFs are very close to this high value and the remaining eight are somewhat further. All in all, five-star 
HOLISTICA Vol 11, Issue 1, 2020, pp. 107-123

ETFs denote much higher mean than one-star ETFs. This lets us know that rational behavior among investors indicates that they should prefer high-rated ETFs during normalization policies.

More specifically, when it comes to analyzing standard deviations in ETFs of both categories it can be seen that no large differences in low-rated compared to high-rated funds are easily traceable.

To be more precise, the highest standard deviation observable in low-rated ETFs is slightly higher than the corresponding highest one in high-rated ETFs. This complies with economic theory and informs the interested agents that investing in one-star ETFs during the QE tapering could be more risky than investing in safer ETFs, though differences are not large.

In an effort to derive a representative picture of the ETFs market, one should bear into consideration that there is higher risk inhibited in high-rated ETFs in comparison to lowrated ones, in general. This could be attributed in that risky assets such as one-star ETFs can prove to provide a reliable investing opportunity when economies have escaped distressed times such as the global financial crisis, thereby monetary policy tends towards normalization.

Furthermore, the one-star rated ETFs show a relatively strong negative asymmetry, as all prices are far below zero. In somewhat similar vein, in the five-star category, negative asymmetry is also observed, but in this case it is not as intense, because the test's values are very close to zero. Moreover, kyrtosis also exhibits differences between the two categories. In the one-star rated ETFs, the curve is leptokurtic, which means that generally we can get higher returns but we assume greater risk. On the contrary, the five-star rated ETFs present a normal distribution, which offers greater security to the investors and policymakers.

The above results are also verified with the assistance of boxplots 1, 2, 3, 4 and 5.

Figure 1 Boxplot of the first group of five one-star rated ETFs

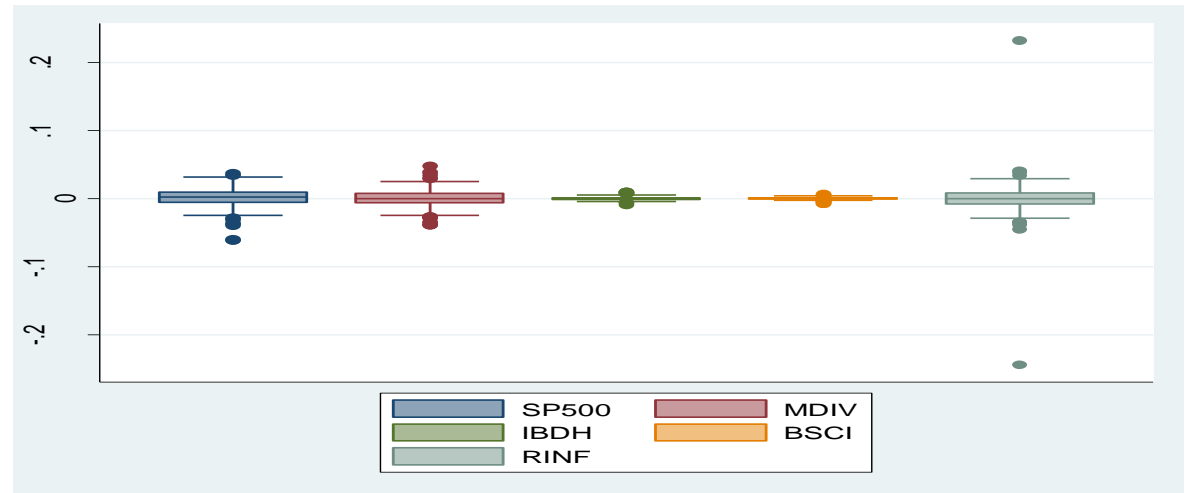


HOLISTICA Vol 11, Issue 1, 2020, pp. 107-123

Figure 2 Boxplot of the second group of five one-star rated ETFs

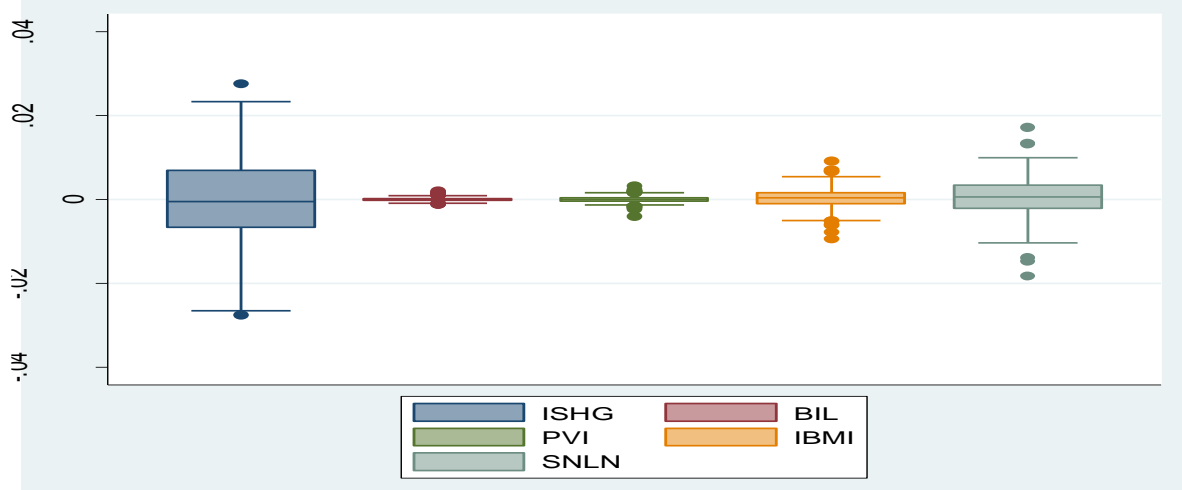

Figure 3 Boxplot of the third group of five one-star rated ETFs

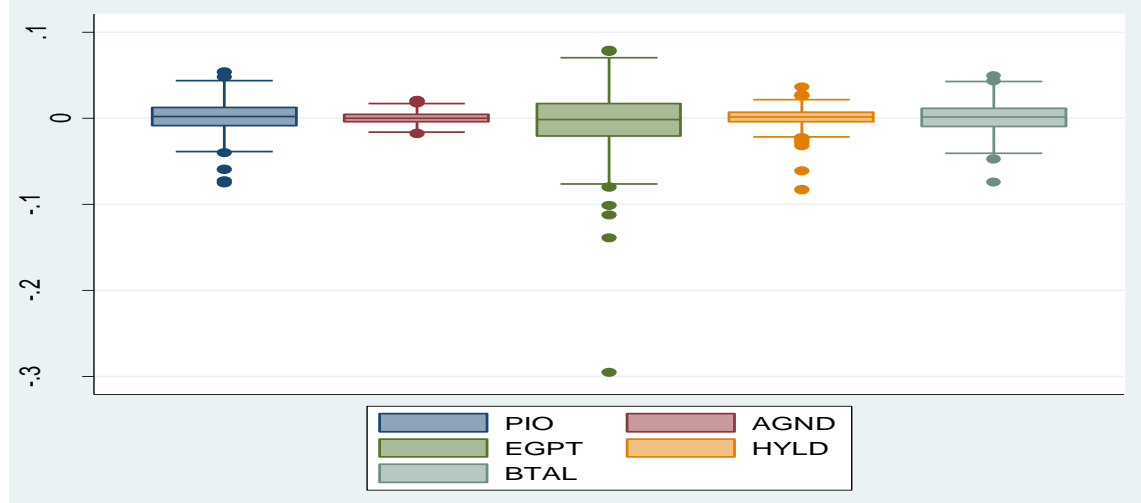

Figure 4 Boxplot of the fourth group of five one-star rated ETFs

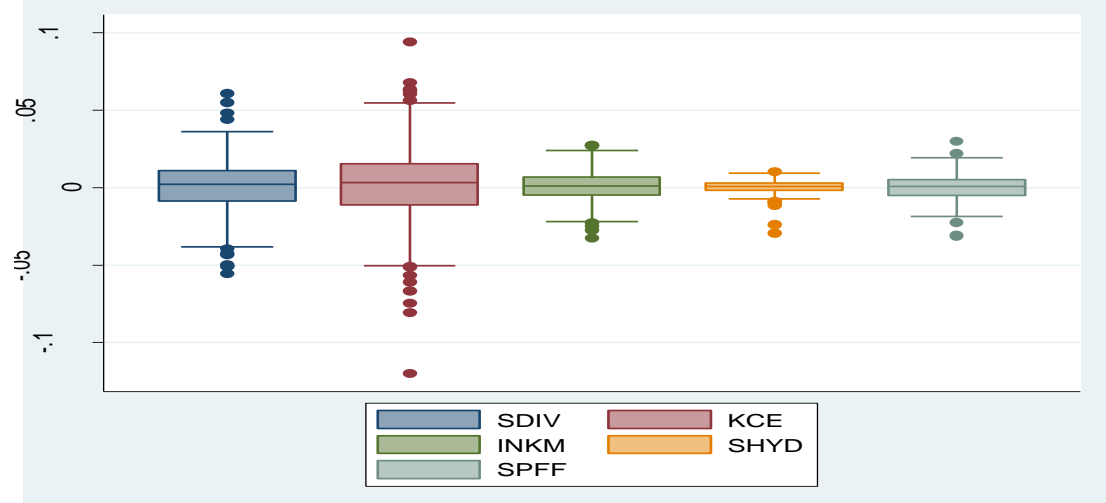

As it can be seen from Figures 1, 2, 3, 4 and 5, the findings that have been extracted so far can be confirmed by the way the observations are gathered in most ETFs. To specify, there is a higher concentration of observations towards the negative values of the boxplots' 
HOLISTICA Vol 11, Issue 1, 2020, pp. 107-123

range and their dispersion is quite small, which means that most observations are gathered around the average observation.

Figure 5 Boxplot of the fifth group of six one-star rated ETFs

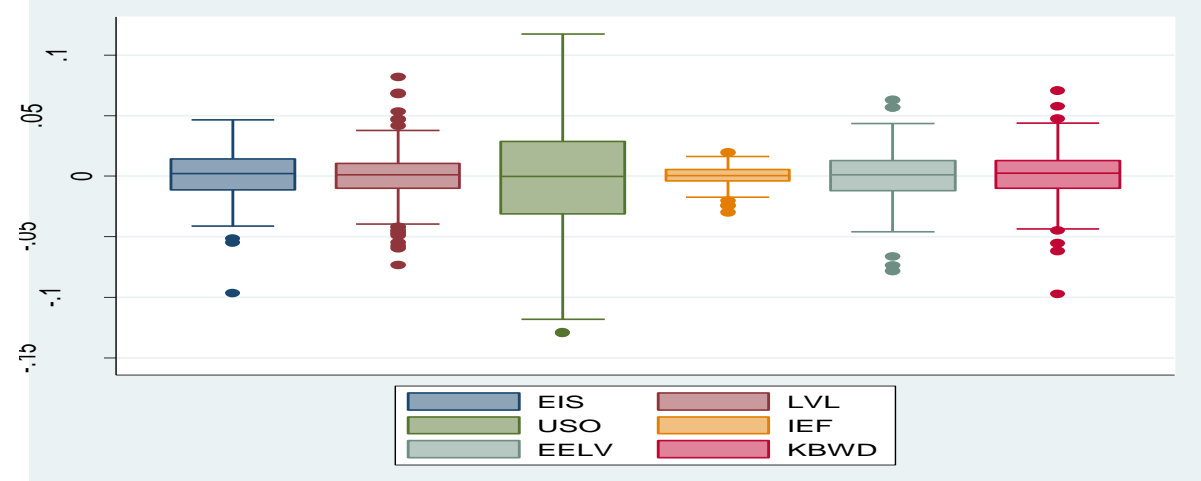

Figure 6 Boxplot of the first group of six five-star rated ETFs

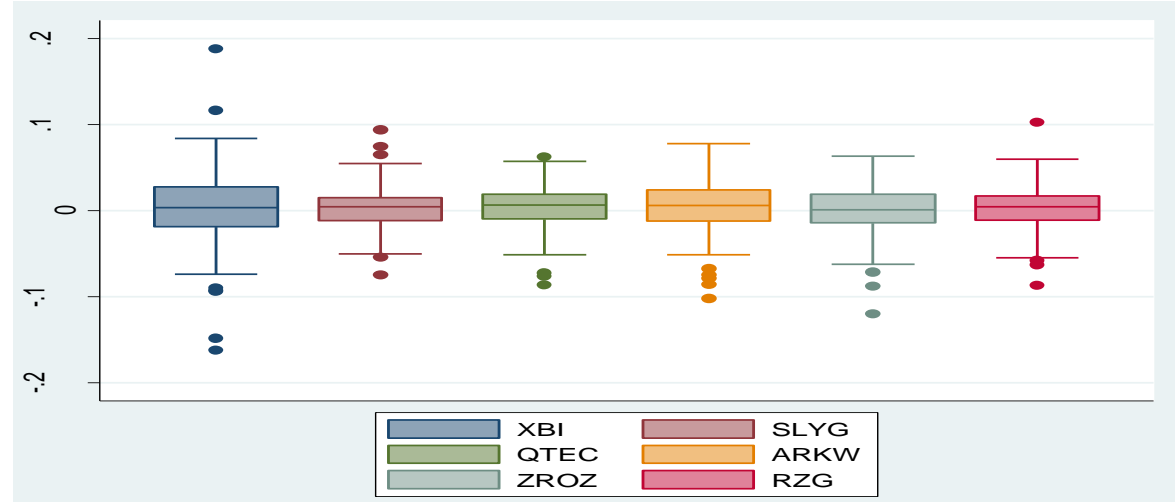

Figure 7 Boxplot of the second group of six five-star rated ETFs

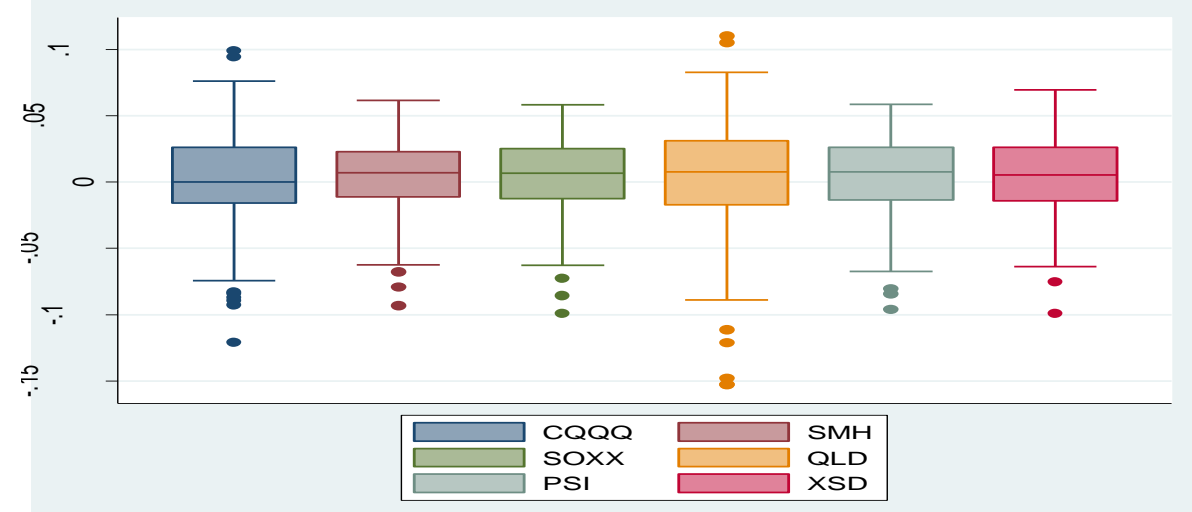

The results which have emerged from the study of the descriptive statistics of the fivestar rated by the Morningstar, ETFs, are verified by Figures 6 and 7 that we listed just above. In particular, we notice that the observations in the boxplots fluctuate in the 
negative range of values, and there appears to be a normal dispersion of observations around the average.

Alpha is defined as a measure of Jensen and is a measure of performance that represents the average return of a portfolio and is comparable to the predicted return resulting from the use of the CAPM model. This measure accurately analyzes the performance and selectivity skills of an investment manager.

- If $a>0$, the manager seems to have the ability to select the appropriate assets.

- If $\mathrm{a}<0$ then the manager does not have specific selective skills.

Beta is a systematic risk measure of a portfolio compared to the market's risk in general. When:

- $b=1$ the ETFs tend to follow the same route as the market

- $\quad b<1$ the ETFs will be less risky than the market and is characterized as "bearish"

- $\quad b>1$ the ETFs have more aggressive behavior than the market and is characterized as "bullish"

In order to find empirical outcomes concerning the Jensen's alpha as well as the beta coefficient, we have employed the well-established Capital Asset Pricing Model (CAPM). Thereby, we have conducted 37 separate regressions after having performed the appropriate tests for autoregression and heteroscedasticity, that is the Dickey-Fuller and the White's tests, respectively. The main equation on which the CAPM is based in this case, is as follows: Excess Returns of ETFs $=a+b \times$ Excess Return of Market Index (SP500)

It should be noted that the Sharpe and Treynor ratios are employed so as to assess the financial performance of each ETF, whereas the Jensen's alpha, the beta and the a/b ratio reveal the selectivity skills, the aggressiveness in relation to the market and the adjusted selectivity skills in relation to aggressive behavior, respectively.

\section{Econometric Results and Assessments}

Interesting results are derived from Sharpe ratio and Treynor ratio calculations as well as econometric estimates. Tables 3 and 4 list the results of our estimates and empirical assessments of returns of low-rated and high-rated ETFs, respectively.

Table 3 Econometric Results of one star-rated ETFs

\begin{tabular}{cccccc}
\hline ETFs & $\mathbf{a}$ & $\mathbf{b}$ & $\mathbf{a} / \mathbf{b}$ & Treynor Ratio & Sharpe Ratio \\
\hline MDIV & -0.00073 & 0.58585 & -0.00125 & -1.15998 & -44.12271 \\
& $(0.314)$ & $(0.000)^{* * *}$ & & & \\
IBDH & 0.00048 & -0.02983 & -0.01624 & 22.78091 & -271.77553 \\
& $(0.006)^{*}$ & $(0.008)^{*}$ & & & \\
BSCI & 0.00033 & -0.02117 & -0.01569 & 32.09692 & -333.95546 \\
& $(0.020)^{* *}$ & $(0.021)^{* *}$ & & &
\end{tabular}


HOLISTICA Vol 11, Issue 1, 2020, pp. 107-123

\begin{tabular}{|c|c|c|c|c|c|}
\hline RINF & $\begin{array}{c}-0.00095 \\
(0.614)\end{array}$ & $\begin{array}{c}0.37407 \\
(0.002)^{* *}\end{array}$ & -0.00255 & -1.81756 & -24.70298 \\
\hline ISHG & $\begin{array}{c}-0.00016 \\
(0.816)\end{array}$ & $\begin{array}{c}-0.11383 \\
(0.015)^{* *}\end{array}$ & 0.00147 & 5.97618 & -65.60720 \\
\hline BIL & $\begin{array}{c}0.00008 \\
(0.014)^{* *}\end{array}$ & $\begin{array}{c}0.00350 \\
(0.105)\end{array}$ & 0.02368 & -194.044 & -1426.23565 \\
\hline PVI & $\begin{array}{c}0.00006 \\
(0.290)\end{array}$ & $\begin{array}{c}-0.00433 \\
(0.271)\end{array}$ & -0.01496 & 69.18021 & -19.47781 \\
\hline IBMI & $\begin{array}{c}0.00025 \\
(0.185)\end{array}$ & $\begin{array}{l}-0.02393 \\
(0.051)^{*}\end{array}$ & -0.01054 & 28.40542 & -251.07179 \\
\hline SNLN & $\begin{array}{c}0.00033 \\
(0.282)\end{array}$ & $\begin{array}{c}0.10369 \\
(0.000)^{* * *}\end{array}$ & 0.00321 & -6.55248 & -145.75949 \\
\hline $\mathrm{PIO}$ & $\begin{array}{c}-0.00089 \\
(0.320)\end{array}$ & $\begin{array}{c}0.90527 \\
(0.000)^{* * *}\end{array}$ & -0.00098 & -0.75014 & -36.13663 \\
\hline AGND & $\begin{array}{c}-0.00009 \\
(0.835)\end{array}$ & $\begin{array}{c}0.11490 \\
(0.000)^{* * *}\end{array}$ & -0.00082 & -5.91659 & -101.03034 \\
\hline EGPT & $\begin{array}{c}-0.00493 \\
(0.056)^{*}\end{array}$ & $\begin{array}{c}0.81504 \\
(0.000)^{* * *}\end{array}$ & -0.00606 & -0.83769 & -18.55265 \\
\hline HYLD & $\begin{array}{c}-0.00028 \\
(0.729)\end{array}$ & $\begin{array}{c}0.30274 \\
(0.000)^{* * *}\end{array}$ & -0.00093 & -2.24499 & -54.98031 \\
\hline BTAL & $\begin{array}{c}0.00122 \\
(0.232)\end{array}$ & $\begin{array}{c}-0.59986 \\
(0.000)^{* * *}\end{array}$ & -0.00204 & 1.13309 & $-39,58209$ \\
\hline SDIV & $\begin{array}{c}-0.00100 \\
(0.308)\end{array}$ & $\begin{array}{c}0.80647 \\
(0.000)^{* * *}\end{array}$ & -0.00124 & 0.84342 & 36.41365 \\
\hline KCE & $\begin{array}{c}-0.00135 \\
(0.281)\end{array}$ & $\begin{array}{c}1.36184 \\
(0.000)^{* * *}\end{array}$ & $\begin{array}{c}-9.94093 \mathrm{E}- \\
10\end{array}$ & $-5 E-07$ & -24.2277 \\
\hline INKM & $\begin{array}{c}-0.00016 \\
(0.767)\end{array}$ & $\begin{array}{c}0.43008 \\
(0.000)^{* * *}\end{array}$ & -0.00038 & -1.57953 & -66.13840 \\
\hline SHYD & $\begin{array}{c}0.00031 \\
(0.335)\end{array}$ & $\begin{array}{c}0.00744 \\
(0.719)\end{array}$ & 0.04173 & -91.348 & -150.18628 \\
\hline SPFF & $\begin{array}{c}-0.00014 \\
(0.792)\end{array}$ & $\begin{array}{c}0.22401 \\
(0.000)^{* * *}\end{array}$ & -0.00064 & -3.03419 & -80.24312 \\
\hline EIS & $\begin{array}{c}-0.00013 \\
(0.909)\end{array}$ & $\begin{array}{c}0.65887 \\
(0.000)^{* * *}\end{array}$ & -0.00020 & -1.03017 & -34.89023 \\
\hline LVL & $\begin{array}{c}-0.00152 \\
(0.197)\end{array}$ & $\begin{array}{c}0.90539 \\
(0.000)^{* * *}\end{array}$ & -0.00168 & -0.75068 & -31.13868 \\
\hline USO & $\begin{array}{c}-0.00463 \\
(0,143)\end{array}$ & $\begin{array}{c}0.72493 \\
(0.000)^{* * *}\end{array}$ & -0.00639 & -0.94116 & -14.90719 \\
\hline IEF & $\begin{array}{c}0.00045 \\
(0.381)\end{array}$ & $\begin{array}{c}-0.15226 \\
(0.000)^{* * *}\end{array}$ & -0.00296 & 4.46467 & -89.02031 \\
\hline EELV & $\begin{array}{c}-0.00148 \\
(0.199)\end{array}$ & $\begin{array}{c}0.83336 \\
(0.000)^{* * *}\end{array}$ & -0.00177 & -0.81569 & -32.85448 \\
\hline KBWD & $\begin{array}{c}-0.00047 \\
(0.664)\end{array}$ & $\begin{array}{c}0.82497 \\
(0.000)^{* * *}\end{array}$ & -0.00057 & -0.8228 & -34.13369 \\
\hline
\end{tabular}


Table 4 Econometric Results of five star-rated ETFs

\begin{tabular}{cccccc}
\hline ETFs & $\mathbf{a}$ & $\mathbf{b}$ & $\mathbf{a} / \mathbf{b}$ & Treynor Ratio & Sharpe Ratio \\
\hline XBI & 0.00020 & 1.33819 & 0.00015 & -0.50553 & -16.10065 \\
& $(0.937)$ & $(0.000)^{* * *}$ & & & \\
SLYG & 0.00081 & 1.07034 & 0.00076 & -0.63251 & -30.4706 \\
& $(0.430)$ & $(0.000)^{* * *}$ & & & \\
QTEC & 0.00115 & 1.21805 & 0.00094 & -0.55528 & -28.5037 \\
& $(0.264)$ & $(0.000)^{* * *}$ & & & -23.3584 \\
ARKW & 0.00305 & 1.25519 & 0.00243 & -0.53717 & -26.1657 \\
& $(0.044)^{* *}$ & $(0.000)^{* * *}$ & & & \\
ZROZ & 0.00128 & -0.43622 & -0.00293 & 1.55690 & -30.2239 \\
& $(0.474)$ & $(0.000)^{* * *}$ & & & -19.6039 \\
RZG & 0.00066 & 1.08067 & 0.00061 & -0.62658 & -25.018 \\
& $(0.527)$ & $(0.000)^{* * *}$ & & & \\
CQQQ & -0.00068 & 1.20091 & -0.00057 & -0.56450 & -23.5922 \\
& $(0.740)$ & $(0.000)^{* * *}$ & & & -15.8612 \\
SMH & 0.00166 & 1.20606 & 0.00138 & -0.56032 & -22.3684 \\
& $(0.232)$ & $(0.000)^{* * *}$ & & & -22.9006 \\
SOXX & 0.00157 & 1.31100 & 0.00119 & -0.51777 & \\
& $(0.279)$ & $(0.000)^{* * *}$ & & & \\
QLD & 0.00140 & 2.27818 & 0.00061 & -0.29565 & \\
& $(0.416)$ & $(0.000)^{* * *}$ & & -0.52120 & \\
PSI & 0.00189 & 1.29567 & 0.00146 & -0.51294 & \\
& $(0.240)$ & $(0.000)^{* * *}$ & & & \\
XSD & 0.00141 & 1.31744 & 0.00107 & & \\
& $(0.353)$ & $(0.000)^{* * *}$ & & & \\
\hline
\end{tabular}

Source: Authors contribution, 2018

In most of ETFs, the alphas we found from the regressions for the one-star rated ETFs are not statistically significant. More specifically, with regard to the case of one-star funds, four of them are statistically significant and among the five-star rated ETFs was only one (The tests were performed with the help of t-statistic and p-value which is in brackets below the observation values). The same applies to the alpha of the five-star rated ETFs, because the majority of them are not statistically significant.

The betas resulting from the regressions of one-star rated ETFs are statistically significant, at their majority. Out of the twenty-five ETFs examined, nineteen exhibited statistically significant betas. Great similarities in statistical significance trustworthiness is detected between low-rated and high-rated ETFs betas, as the latter are also statistically significant.

A better measure of ETF performance is provided by the ratio of the selectivity skills coefficient to the beta coefficient. The combination of these two measures (a / b), shows how competent the fund manager is, in terms of how aggressive he is according to the market. It should be noted that the SHYD ETF among one-star rated funds presents the higher $\mathrm{a} / \mathrm{b}$ ratio and its value equals 0.04173 . It can be easily observed that among the 25 one-star ETFs only five approximate this high value, in contrast to the rest of low-rated 
ETFs that present much lower values. It should be emphasized that five-star ETFs are denoted to take lower $\mathrm{a} / \mathrm{b}$ values but there is not large width in their values. It can be highlighted that low-rated ETFs present much lower a/b values in comparison to highrated ETFs. One should not neglect that approximately all a/b values in low-rated ETFs are negative, whereas, the opposite holds for high-rated a/b quotes which are positive in their great majority. Intriguingly, this abides by economic theory that indicates high-rated ETFs being more profitable for investors without having to bear large levels of risk.

By studying the outcomes concerning the Sharpe index, it is discernible that the majority of ETFs exhibit negative values. In those rated as one-star, in only one case the result is positive. In those rated as five-stars, they all present low returns, thereby low Sharpe ratios. The Sharpe's performance index uses the standard deviation of returns as a measure of total risk, while the Treynor performance index uses beta systemic risk, which in fact is the market's risk. We conclude that according to the Sharpe index that presents negative values for both low-rated and high-rated ETFs, investing in either of these categories during the QE-tapering period is perhaps not a profitable action.

According to the Treynor results derived, ETFs of both rating groups, performance is also low. This is owing to most of the results being derived as negative and presenting high values only in a few cases. Specifically, out of 25 one-star rated ETFs, only eight have a high Treynor ratio and among those rated with five-stars only one is positive.

In the linear regressions we have conducted by employing the returns of ETFs, it is found that fund managers do not exhibit particular selectivity skills in either type of ETFs. On the other hand, beta was statistically significant in all cases. To be more precise, in the category of one-star rated ETFs have more defensive behavior than the market, while the five-stars rated ETFs are more aggressive. From the previous findings it is clear that different categories of ETFs present not identical tendencies to act aggressively.

\section{Conclusions}

To recapitulate, the sample in question consists of 37 global ETFs, which are placed in the period of the US restrictive policy (QE Tapering). The Sharpe and Treynor measures based on the Capital Asset Pricing Model (CAPM) were employed to assess them.

The 25 ETFs that have been rated by Morningstar with one-star and the remaining 12 with five-star, which means they have the lowest and highest credit ratings, respectively, compared to other similar ones but also to the market itself. It should be emphasized that this study has undertaken this comparison, because these ETFs refer to extreme cases and are among the most important matters in the field of economics. Descriptive statistics have been adopted to offer a more accurate picture of the risk-return nexus in ETFs. In the case of the one-star rated ETFs, the distribution of the observations is negatively asymmetric, whereas the same is found concerning high-rated ETFs but in a lesser extent.

Furthermore, linear regressions based on the well-established CAPM model have taken 
HOLISTICA Vol 11, Issue 1, 2020, pp. 107-123

place in order to extract the alphas and betas referring to the selectivity skills of the manager and the systemic market risk, respectively. It should be emphasized that the managers' selectivity skills are weak, as Jensen's alphas are not statistically significant and most of them are negative both in low-rated and high-rated ETFs. Regarding the betas, they are statistically significant in most cases, which means they present a more aggressive behavior than the market. Concerning the Sharpe's and Treynor's measures, one can see that they generally present low values. In particular, both Treynor's negative values, which only take into account the systemic risk, and the corresponding Sharpe's indexes, which refer to the overall risk, show that ETFs of both ratings do not constitute reliable investment options if the risk-return nexus is taken into consideration. Moreover, an additional measure that was taken under consideration is the combination of these two measures ( $\mathrm{a} / \mathrm{b}$ ) and the nexus between fund manager's selectivity skills and the systematic risk of market. To be more precise, low-rated ETFs appear higher values, this measure, than the high-rated ETFs.

The added value of our research into existing academic work is that we cast light in an innovative aspect of financial markets and monetary policymaking that is we investigate the unchartered waters of the performance of sophisticated financial instruments during the normalization period that followed the quantitative easing eras. The findings of this paper should help interested investors and central planners to make better decisions when economies escape from turbulent eras and their antidotes.

\section{References}

Agapova, A. (2011). Conventional mutual index funds versus exchange-traded funds, Journal of Financial Markets, vol. 14, no. 2: 323-343.

Aizenman, J., Mahir B., \& Hutchison, M.M. (2014). The transmission of Federal Reserve tapering news to emerging financial markets. no. w19980. National Bureau of Economic Research.

Avramov, D., \& Wermers, R. (2006). Investing in mutual funds when returns are predictable, Journal of Financial Economics 81, no. 2: 339-377.

Blume, M. E., \& Irwin F. (1973). A new look at the capital asset pricing model, The journal of finance 28, no. 1: 19-34.

Bollen, N. PB., \& Jeffrey, A. B. (2001). On the timing ability of mutual fund managers, The Journal of Finance 56, no. 3: 1075-1094.

Bollerslev, T., Engle, R. F., \& Wooldridge, J. M. (1988). A capital asset pricing model with timevarying covariances, Journal of political Economy 96, no. 1: 116-131.

Carhart, M. M. (1997). On persistence in mutual fund performance, The Journal of finance 52, no. 1: $57-82$.

Chari, A., Dilts Stedman, K., \& Lundblad, C. (2017). Taper tantrums: QE, its aftermath and emerging market capital flows. no. w23474. National Bureau of Economic Research.

Chen, S.-N., \& Hoyoon, J. (1994). On selectivity and market timing ability of US-based international mutual funds: Using refined Jensen's measure, Global Finance Journal 5, no. 1.

Edelen, R. M., \& Warner, J.B. (2001). Aggregate price effects of institutional trading: a study of mutual fund flow and market returns, Journal of Financial Economics 59, no. 2: 195-220.

Engen, E. M., \& Lehnert, A. (2000). Mutual funds and the US equity market, Fed. Res. Bull. 86: 797. 
HOLISTICA Vol 11, Issue 1, 2020, pp. 107-123

Engle, R.F., \& Sarkar, D. (2006). Premiums-discounts and exchange traded funds, The Journal of Derivatives 13, no. 4: 27-45.

Fama, E. F., \& French, K.R. (1996). The CAPM is wanted, dead or alive, The Journal of Finance 51, no. 5: 1947-1958.

Fama, E. F., \& French, K.R. (2006). The value premium and the CAPM, The Journal of Finance 61, no. 5: 2163-2185.

Fawley, B. W., \& Neely, C. J. (2013). Four stories of quantitative easing, Federal Reserve Bank of St. Louis Review 95, no. 1: 51-88.

Firth, M.A. (1977). The investment performance of unit trusts in the period 1965-75, Journal of Money, Credit and Banking 9, no. 4: 597-604.

Frazzini, A. \& Pedersen, L.H. (2014). Betting against beta, Journal of Financial Economics 111, no. 1: 1-25.

Gastineau, G. L. (2001). An introduction to exchange-traded funds (ETFs), Journal of Portfolio Management and Economics 27, no. 3: 88-96.

Hallahan, T. A., \& Faff, R. W. (1999). An examination of Australian equity trusts for selectivity and market timing performance, Journal of Multinational Financial Management 9, no. 3-4: 387402.

Harper, J. T., Madura, J., \& Schnusenberg, O. (2006). Performance comparison between exchangetraded funds and closed-end country funds, Journal of International Financial Markets, Institutions and Money 16, no. 2: 104-122.

Hayat, R., \& Kraeussl, R. (2011). Risk and return characteristics of Islamic equity funds, Emerging markets review 12, no. 2: 189-203.

Henriksson, R. D., \& Merton, R. C. (1981). On market timing and investment performance. II. Statistical procedures for evaluating forecasting skills, Journal of business, 54, no.4: 513533.

Hübner, G. (2005). The generalized Treynor ratio, Review of Finance 9, no. 3: 415-435.

Jensen, M.C. (1968). The performance of mutual funds in the period 1945-1964, The Journal of finance 23 , no. 2: 389-416.

Joyce, M. AS., \& Tong, M. (2012). QE and the gilt market: a disaggregated analysis, The Economic Journal 122, no. 564: F348-F384.

Kaimakamis, G., \& Kiriakopoulos, K. (2010). A note on Temporal Aggregation Effects on the Mean Variance Portfolio. Optimization Approach-Some Empirical Results, Journal of Financial Decision Making 6, no. 1: 69-76.

Klemkosky, R. C., \& Martin, J. D. (1975). The adjustment of beta forecasts, The Journal of Finance 30, no. 4: 1123-1128.

Kostovetsky, L. (2003). Index mutual funds and exchange-traded funds, The Journal of Portfolio Management 29, no. 4: 80-92.

Koulis, A., Botsaris, C., Adam, M., \& Beneki, C. (2011). An assessment of the performance of Greek mutual equity funds selectivity and market timing, Applied Mathematical Sciences, 5(4), 159-171

Lhabitant F. S. (2001). On Swiss timing and selectivity: in the quest of alpha, Financial markets and portfolio management, 15(2): 154-172.

Lockwood, L. J. (1996). Macroeconomic forces and mutual fund betas, Financial Review 31, no. 4: 747-763.

MacKinlay, A. C. (1995). Multifactor models do not explain deviations from the CAPM, Journal of Financial Economics 38, no. 1: 3-28. 
Madhavan, A. (2012). Exchange-traded funds, market structure, and the flash crash, Financial Analysts Journal 68, no. 4: 20-35.

Malkiel, B. G. (2014). Is smart beta really smart?, The Journal of Portfolio Management 40, no. 5 : 127-134.

Markowitz, H. (1952). Portfolio Selection, Journal of Finance, 7, no 1. : 77-91.

Morgan, I. G. (1975). Prediction of return with the minimum variance zero-beta portfolio, Journal of Financial Economics 2, no. 4: 361-376.

Mossin, J. (1966). Equilibrium in a capital asset market, Econometrica: Journal of the econometric society, 34, no. $4: 768-783$.

Newey, W.K., \& West, K.D. (1986). A simple, positive semi-definite, heteroskedasticity and autocorrelationconsistent covariance matrix, Econometrica: Journal of the econometric society 55, no. $3: 703-708$

Pettengill, G.N., Sundaram, S., \& Mathur, I. (1995). The conditional relation between beta and returns, Journal of Financial and quantitative Analysis 30, no. 1: 101-116.

Philippas N. (2001). An empirical evaluation of the performance of the Greek Fund Managers, Spoudai Magazine, University of Piraeus, 51(1-2): 142-163.

Reinganum, M. R. (1981). A new empirical perspective on the CAPM, Journal of financial and quantitative analysis 16, no. 4: 439-462.

Romacho, J. C., \& Cortez, M.C. (2006). Timing and selectivity in Portuguese mutual fund performance, Research in International Business and Finance 20, no. 3: 348-368.

Shanken, J. (1985). Multivariate tests of the zero-beta CAPM, Journal of financial economics 14 , no. 3: 327-348.

Shanken, J. (1992). On the estimation of beta-pricing models, The review of financial studies 5, no. 1: 1-33.

Sharpe, W. F. (1964). Capital asset prices: A theory of market equilibrium under conditions of risk, The journal of finance 19, no. 3: 425-442.

Sharpe, W.F. (1966). Mutual fund performance, The Journal of business 39, no. 1: 119-138.

Treynor, J., \& Mazuy, K. (1966). Can mutual funds outguess the market, Harvard business review 44, no. 4: 131-136.

Ünal, G., \& Tan, Ö.F. (2015). Selectivity and market timing ability of polish fund managers analysis of selected equity funds, Procedia-Social and Behavioral Sciences 213: 411-416. 